\title{
TECHNOLOGY, NORMATIVITY, AND THE FUTURE: THE ARISTOTELIAN TURN
}

Henk Procee, University of Twente

INTRODUCTION

In our postmodern era all certainties seem to have gone. Neither the idea of progress nor standard ethical theories have apparently retained enough power to guide humanity. As a result, technologists find themselves in a paradoxical situation. While they demonstrate increased reality-changing activity, they are increasingly losing the instruments to effectuate their responsibilities for the future of the species. Two reactions to this state of affairs are possible. The first way is to accept this condition passively. This reaction consists of hardly more than hoping and praying. The second way is more active. That reaction consists of bringing about alternative routes to tackle the responsibilities of technologists. Providing such a reconceptualization is the aim of this paper. Its starting point is rooted in the old A ristotelian philosophy.

However embarrassing this might sound, the claim will be defended that the basic structure of A ristotle's ethics (quality of character in changing circumstances) is highly relevant for a fresh approach to forming the "virtuous engineer."

\section{THE POST MODERN CONDITION OF ENGINEERS}

Engineers have an important role in the shaping of the human future. By inventing and maintaining new technological products and processes they have a great impact on the world in which people live and will live. As a consequence of this they should shoulder special responsibilities. In addition to their obvious, but important, technical responsibility - they have to meet the standards of their field of competence and the requirements of the product specifications-they are charged with having a responsibility for the societal effects of their activities in the long run. This social responsibility is based on the assumption that engineers have a privileged insight into the consequences of technology. 
Under the aegis of the ideology of Progress these two types of responsibility (technical and social) were presumed to go hand in hand. The cunning of reason would place the many small scale activities and effects within a broad socially and culturally desired whole, the technological paradise. On the basis of this ideology the long run social responsibility was sufficiently met by the short term technical responsibility.

This state of innocence was of short duration. Instead of applauding technological blessings, many critics talked about dangers, disasters, and the M oloch character of technology. These critics stressed the social responsibility of engineers as opposed to their technical responsibility. In their view technology had to be tamed by ethics. Two ethical theories, Kantian deontology and utilitarian teleology, were supposed to handle this difficult task.

This small history of ideas has some ironic overtones. In line with postmodern ideas some fundamental objections can be raised against the proponents as well as the critics of technological progress. In spite of their differences they have a lot in common. They agree on the conceptualization of technology, reason, and progress as homogeneous entities. However, we have to accept their essentially heterogeneous character. Within technology we have to distinguish a plurality of unrelated technological domains, methodologies, artifacts, and so on. The idea of a homogeneous reason supposed to be the (external) guide of humankind, either in a scientific-technological embodiment or in an ethical-theoretical one, has to be abandoned. In our relativistic era we not only know that rationality has many faces, but also that it is rather powerless. In accordance with these criticisms, the idea of homogeneous progress (either in the form of a blessing or in the form of a disaster) has to be given up. Progress just has a local character, rather than a global one.

Because of all these kinds of heterogeneity general statements regarding the responsibility of technologists can hardly be made. But the situation is even worse. The presupposition of the most influential ethical theories, to wit a certain constancy and universalism of human preferences, has been weakened by technology itself. Technological inventions change the world people inhabit and the criteria in accordance with which they evaluate their situation. As a result the post modern condition of technologists appears tragic. Engineers are facing an increasing responsibility for the human future, although in a context in which 
almost all (classical) approaches seem to fail.

This condition is in need of consideration and reconsideration. In my view, accepting the postmodern description of heterogeneity does not imply accepting the impossibility of normative action. Instead of passivity or even irony, it will be important to reformulate what it means to act responsibly, what it means to be a good engineer. In this paper this problem will be tackled with the help of an old ethical theory. In this theory character is the central element, instead of reason or action. It stems from A ristotle' sN icomachean E thics. F or A ristotle character (or virtue) is the central concept: the ability to act responsibly in new and unknown circumstances. His approach may lead to some interesting analytical and normative tools for interpreting the ways technologists learn, act, and behave.

After a short explication of the A ristotalian ethics it will be placed within a social context which can embody it. That context has been phrased by A lasdair $\mathrm{M}$ aclntyre as "practice." Because this concept combines descriptive and normative elements it will be suitable for analyzing the situations and responsibilities of engineers. Both concepts (virtue and practice) may shed some new light on various problems: the tensions between technological practices and socioeconomic institutions; the nature of techno-professional normativity and ways to foster it; the relation of the internal normativity of practices to the two other types of normativity (technical and social). In conclusion a special topic will be attended to: the cultural and existential importance of the concept of trust.

\section{FROM VIRTUE TO PRACTICE}

The ethical theory of A ristotle sounds simple: virtue is the attitude of choosing the right middle. In concrete situations a virtue in combination with a rational analysis of the specific circumstances brings about a justified course of action. For example, having the virtue of being a brave man sometimes leads to fighting, sometimes to fleeing, depending on the specific characteristics of the situation. It is important to note the aspect of learning and maintaining of virtues. They are not naturally given, but are the product of lifelong exercising. In judging people's activities, the results of their behavior are not at stake, but their attitude. Of course, A ristotle claims, we may have some reason to think that the right attitude will probably lead to desirable results. 
In relation to deontological and teleological theories two differences can be distinguished. First, normative judgment regards character and not (the results of) actions. Second, instead of an algorithmic approach on the basis of universalistic principles A ristotle's ethics stresses a more heuristic approach in terms of attitudes. By implication it is underdefined how to act in concrete situations. The combination of character and context does not generate criteria for definitive decisions. It was this problem that led teleologists to their computational approach of preferences (the greatest happiness or utility for the greatest number). Two counterarguments are relevant here. First, as we have seen, this computational approach sometimes misses the point in technological contexts, because preferences may change as a result of technological in(ter)ventions. $\mathrm{Next}$, the problem of underdetermination of action can be viewed as a benefit, rather than a loss. It gives space to personal and professional responsibility, instead of insisting on general outcomes of calculated data.

A nother problem is more urgent. It can be stated in the form of a question: Which virtues? For A ristotle, typical masculine Greek virtues, such as bravery, modesty, magnanimity, love of truth, and justice, formed the heart of his ethical system. In the Christian tradition faith, hope, and love became the virtuous three. Greek virtues, Christian virtues, which of them and which of the many other virtues should get priority? The deontological approach of Kant can be viewed as an attempt to resolve this problem once and for all. Through all differences he saw one common denominator of virtue: good will. Taking good will as his starting point, he analyzed its structure in such a way that it could stand above all the mentioned virtues. To be universalistic good will should have an abstract character, and not be substantiated by any cultural or religious content. The only way to meet this condition for Kant was to restate good will as analogous to a (scientific) law. This led to the introduction of themeta-virtue of universalization (categorical imperative). Kant himself was not al ways consistent in his approach. Sometimes he used, and in my opinion rightly so, the meta-virtue of universalization as a different level of normative consideration. In other places he suggested that his theory could substitute for all other ethical theories, which implies that his meta-virtue would have the same standing as the classical or Christian virtues. I agree with postmodern criticisms on the last interpretation of $K$ ant' s ethics. N evertheless, I do not wish to give up the first one. It is most important to retain his meta-virtue of honesty, of the right to speak, of the duty to listen-in short the moral space in which people can deliberate about the virtues 
which are appropriate (H abermas).

Having given due credit to Kant's meta-position, the problem of which virtues on the object-level is still unresolved. To tackle that problem, an abstract universalistic position is not very instructive. V irtues do not exist in a social vacuum, but are part and parcel of human (and also technological) practices. We have to turn to these embodiments of virtues to clarify the real power of A ristotle' s ethics for today's technological culture.

\section{PRACTICES IN ACTION}

The concept of practice has been elaborated by A lasdair $M$ aclntyre in his book, After Virtue. Here is a clear description, worth quoting:

[A practice is] any coherent and complex form of socially established co-operative human activity through which goods internal to that form of activity are realised in the course of trying to achieve those standards of excellence, which are appropriate to, and partially definitive of, that form of activity, with the result that human powers to achieve excellence, and human conceptions of the ends and goods involved, are systematically extended ( $p$. 187).

Some examples may illustrate this definition. Throwing a football with skill is not a practice, but the game of football is. Bricklaying is not a practice, architecture is. The range of practices is wide: arts, sciences, games, politics, farming, all fall under the concept. Within each practice a great variety of activities are carried out: the writing of essays, the planting of turnips, the stopping of penalty shots by goalkeepers, the performance of operations by surgeons. Practices are, and that is the first part of the definition, socially established forms of human activities from which those activities get their meaning and value. There are two kinds of valuation to discern:

a. Internal goods, which are essential to a practice, such as beauty, elegance, depth, originality. Participants in a practice compete with each other to show their own excellence and to foster their practice. The results of this kind of competition are likely to be advantageous for every member of that practice. For 
that reason it is opportune to use the expression, "goods internal to that practice." In another sense it is also appropriate; only members of that practice can judge the qualities of their fellow participants. For example, to be able to value the depth of Fischer and the originality of Bronstein, one needs to be a rather good chess player.

b. External goods, which are contingently attached to practices by the accidents of social circumstance. They mostly have the appearances of money, prestige, and power. Competition for external goods generally leads to winners and losers, rather than to an improvement of the practice at hand.

Being an excellent practitioner does not mean earning a lot of money, but first and foremost getting admiration by fellow practitioners. It is interesting to note that Thomas Kuhn's philosophy of science corresponds very well with this concept of practice: a scientific community, centered around a central paradigm, values its members in the measure of their success within their domain of inquiry. Following $\mathrm{M}$ aclntyre in his description of practices some characteristics can be added:

-To enter into a practice is to accept the authority of the internal standards and the (in)adequacy of their own performances as judged by them. It is to subject the personal attitudes, choices, preferences and tastes to standards which currently and partially define the practice.

-Practices are basically different; they have a local character, defined by their own rules and goods.

- Practices also have a history; the rules and standards of games, sciences, and arts are themselves not immune to criticism and change. To improve the practice, to make progress in the specific field, can imply changes in the central conceptions.

-Every practice requires a certain kind of relationship between those who participate in it. They are entitled to co-operation under the banner of the standards of the practice in order to reach the objectives headed under "internal goods."

In my view, the concept of practice is a useful tool for analyzing the role of technologists in shaping the future. By stressing the multitude of practices it is an antidote against a unifying concept of technology. By conceptualizing 
practitioners as members of a (technological) community it leads engineers out of their alleged solitude which is implied by the vision of technical normativity. By enabling the articulation of specific central norms of (the members of) practices it might lead to the formulation of professional (ethical) codes.

M oreover, the acceptance of heterogeneity sharpens the eyes to discern tensions at different frontiers: (a) tensions between different practices, (b) tensions between practices and society in general, (c) tensions between practices and institutions.

Starting with tensions between different practices, practitioners of different blends do not have overarching criteria for success; they speak different languages; and they have different world views. Disputes between them are mostly ineffectual. N otwithstanding the negative impact of this description, insight into this type of tensions can be helpful for the needs of heterogeneous communication. (Recall Kant on extended thinking.). Tensions between practices and society in general can be illustrated by the sport of boxing. Cassius Clay, alias M ohammed Ali, has contributed in a fascinating manner to the quality of this practice. $\mathrm{H}$ is style of boxing has led to a new norm of excellence. $\mathrm{N}$ otwithstanding the recognition of his excellence, from a general ethical point of view (it is morally wrong to beat fellow humans) one can refuse this specific practice. This tension implies the need for insight into the relation between practice and society. W ithin society tensions between practices and institutions are frequent. The difference between both is one of the most essential findings of $\mathrm{M}$ acIntyre. Chess, chemistry, and medicine are practices; chess clubs, laboratories, and hospitals are institutions. Institutions are necessary for the flourishing of practices, by contributing to their basic financial and institutional preconditions. They may foster or even withdraw the space of existence of specific practices. However, institutions have their own goals, which may be in contradistinction to the goals of practices. In particular, many technologists are situated on the sharp frontier between the practice, in which they have been educated, and the institution, in which they work. In the institutional context the role of external goods (profits, products for a market, and so on) may exceed many times the role of internal goods.

The concept of practice is a useful tool for analytical purposes, for description and interpretation. It takes professionals seriously as conscious 
workers in all kinds of heterogeneous situations. It gives space to the clarification of the many tensions which can make their lives so rewarding and difficult. For prescriptive purposes, it stresses the need for internal debates on the central practice normativity, as well as for the explication of the role of practices in society as a whole. These aspects lead to the next section in which the virtuous professional will be the main topic.

\section{THE VIRTUE OF PRACTICAL NORMATIVITY}

The activities of engineers are essentially normative. They try to come from a less satisfying situation to a more satisfying one (Romiszowski). They work in the light of specific norms. The emergence of those norms can follow different paths.

a. Stressing only methodological-technical requirements, the norms will come from external sources, such as employers, markets, governments.

Engineers just have to perform their job according to the best possible technical criteria, without taking into consideration further reaching responsibilities. (If they nevertheless act in such a way, they do so in the role of citizen, not in the role of engineer). This position gets its ideological backing from the (logical-positivistic) view that technology is applied science.

b. Stressing also societal-ethical normativity, the norms can emerge from a deliberation between technologists and all other affected people in which they formulate a common project. This approach, proposed by Habermas, differs from the previously mentioned social responsibility. In that case ethical consideration should place boundaries on technological activities; in this approach co-operation between variously involved groups is emphasized.

c. Stressing the quality of the technological practice itself, the norms will stem from that practice. The previous section has demonstrated different examples of this.

This short list has some peculiarities, worth mentioning. For most technologists and also non-technologists the first path represents the dominant ideology. Thanks to $\mathrm{H}$ abermas a valuable alternative has some credit. In accordance with the second path two techniques have recently been developed to approach the 
future in a non-linear way. In both empirical and normative elements are coupled. The first technique is called scenario-building. (See for example the many publications of the Dutch Central Plan Bureau in the Hague.) It applies especially to societal domains like traffic, environment, and education. For each domain a number of alternative future descriptions are elaborated on the basis of the most plausible empirical assumptions in combination with a variety of normative positions people might embrace. This technique has some advantages: people are able to choose on the basis of the knowledge of the effects of their choices; the future is partly in their hands; political discussions increase in substance. Nevertheless, at least one problem remains unsolved: the changing of preferences brought about by the change of time and context. To overcome this problem a second technique has been introduced: Constructive Technology A ssessment (Rip and $\mathrm{M}$ isa). CTA aims at more than the building of scenarios and the choice between them. It will contribute to processes of reflection in the course of processes of technology development. This means that every step is open to new deliberation, in such a way that the different actors can (technologically and ethically) act and learn together. A $n$ important assumption is the (relative) openness of the future. For different reasons (who is involved, who is excluded in the reflective process; how can oppositions be bridged) this technique is rather complex. Nevertheless, scenario-building and CTA demonstrate the normative richness of combining two previously separated domains of responsibility.

The third path of norm emergence takes the norms from the practice itself. Scientific research leads to next generations of research; artistic performances lead to new kinds of art. Practices which only have an internal logic, like sports and arts, can be sufficiently characterized by their own dynamics, although to what extent depends on institutional factors. In the technological domain, however, practices not only have an internal logic, they also have an external point. In medicine, for example, the central norm can be stated in two ways: promoting (physical) health and diminishing (physical) suffering. It would be interesting to dwell on these differences, but for the argument at stake it would suffice to mention their relation to the world outside the practice. This is typical in the case of technological practices: they have their own normativity related to external elements. On the basis of this structure debates on the central normativity may foster the quality and the effectiveness of the practice. Doctors may dispute the two norms, to come to a better understanding of what it means to be a good doctor. Even military researchers may consider al ternatives for land mines (for 
example designing their active life span not to exceed six months) from the normative position that they really want to work on defensive weapon systems.

These examples lead to the heart of virtuous practices. Basic to the previous examples is the assumption that practices will have their own logic, their own normativity, worth being defended against external institutional forces and worth being improved by internal debates. The concept, "virtue of practical normativity, " may lead to a number of consequences.

To start with, it may emphasize the formulation of professional codes in which groups of practitioners describe the quality requirements of the work to be done and of the members to be admitted to their group. A lthough the status of such descriptions may run from a rather loose heuristic formulation to a strongly disciplined one, with regard to the content two (extreme) directions are open.

One direction stresses the (relative) autonomy of the practice, leading to the protection of one's domain against invasion by external pressures. The anarchistic ideas put forward by Paul Feyerabend (protect society from scientists, protect scientists from philosophers) can be extended to engineers: protect professionals from market imperatives. Ideas about a "risk-society," developed by Ulrich Beck, can find a specific elaboration in this special context: let practitioners play their own game, not directed to some specific social or economic benefit.

A nother elaboration of professional codes emphasizes the external point of a practice, leading to societal-ethical consequences. In such codes not only responsibilities for the internal quality but also for external objectives are formulated. Examples are professional medical codes and codes of educators. For hard boiled technologists such codes, with the exception of a few proposals, hardly exist (Hogenhuis). A lthough some causes may be put forward to explain this situation, nevertheless, proposals aiming in that direction might be valuable. $\mathrm{N}$ ot only for ethical reasons (it may be helpful in a moral dilemma to get institutionalized support from peers), but also for giving an impulse to the self-image of the technologist in the (new) sense of being a virtuous engineer.

Stressing the practice-related virtues may even lead to new insights in the central normativity of practices themselves. In these days much attention is given 
to environmental aspects of technology. Within a purely instrumental approach to technology this implies adding some environment-related specifications to the usual course of action; by accepting environment as an essential part of the central normativity, a totally new concept of engineering would be possible, and this might lead to unorthodox approaches of research and development.

\section{CONCLUSION}

The highlighting of virtue and practice stems from two basic ideas. The first is the conceptual and emotional poverty of the usual approach to normative action. Being situated in the dichotomized field of technical versus social responsibility, technologists are presumed to serve so many masters that the outcomes may vary from schizophrenia to total indifference. The concept of practice has been introduced to analyze the condition of professionals in more dimensions than only two. It has also been introduced to clear the grounds for fresh ideas on being a good engineer.

The second reason to introduce the concepts of virtue and practice stems from cultural or even existential arguments. It is based on taking the realitychanging power of technology seriously. Although the ideology of solid scientific data is very strong (any manager who wants to make a decision will demand more exact figures than science can deliver; any patient desires more medical research than is healthy for him), this assumption is not correct for activities concerning the future. Taken technically and existentially, the ideology of certainty misses the point of humanity. In the long history of humankind the idea of calculating the future was a product of the Enlightenment, having no firm grounds before and having lost its credibility thereafter. Instead of certainty a different code word has to be coined: trust. Trust is based on experiences of the past and on hope (rather than data) for the future. In terms borrowed from $\mathrm{K}$ ant, we might say that trust is a regulative concept, worth revitalizing.

The emphasis laid on the concepts of virtue and practice is aimed at restoring the importance of the idea of trust. As well for humanity as for technologists such an approach may be valuable, by making people less frightened and by making practitioners more self-confident.

\section{REFERENCES}


A ristotle. Nicomachean Ethics (various editions).

Beck, Ulrich. 1992. Risk Society: Towards a New Modernity. London: Sage.

Feyerabend, Paul K. 1975. Against M ethod. London: New Left Books.

Habermas, Jurgen. 1981. Theorie des kommunikativen Handelns. Frankfurt.

Hogenhuis, C. T. 1993. Beroepscodes en morele verantwoordelijkheid in technische and natuurwetenschappelijke beroepen. 1993 [Professional codes and moral responsibility in technological and scientific professions]. Zoetermeer/D riebergen: M inisterie van Onderwijs.

Kuhn, Thomas S. 1970. The Structure of Scientific Revolutions. Chicago: University of Chicago Press.

Maclntyre, Alasdair. 1981. After Virtue. London: Duckworth.

Procee, Henk. 1977. De nieuwe ingenieur; over techniekfilosofie en professioneel handelen [The new engineer; about philosophy of technology and professional activity]. Boom:M eppel.

Rip, A rie, and Thomas J. Misa. 1995. M anaging Technology in Society: The Approach of Constructive Technology Assessment. London: Pinter.

Romiszowski, A.J. 1981. Designing Instructional Systems. London: Kogan/Page. 